\title{
Bacteriemia por Streptococcus pyogenes. Presentación de un caso clínico con aparición tardía de neumonía
}

\section{CAROLINA RAMÍREZ ${ }^{a}$, JUAN PABLO ARAB ${ }^{\mathrm{a}}$, GONZALO EYMIN ${ }^{1}$ \\ Pneumonia caused by Streptococcus pyogenes. Report of one case}

We report a 58-year-old female presenting with fever and vomiting. The initial laboratory examination disclosed two blood cultures that were positive for Streptococcus Pyogenes. An abdominal CAT scan showed a right basal pneumonia. The patient was treated with antimicrobials and discharged with oral cefadroxil for 21 days. One month after discharge she was asymptomatic and with a normal C reactive protein. Pneumonia is an important differential diagnosis in unknown origin bacteremia caused by Streptococcus Pyogenes. It may have a fulminant evolution and may complicate with abscess and empyema.

(Rev Med Chile 2010; 138: 847-851).

Key words: Bacteremia; Pneumonia, bacterial; Streptococcus pyogenes.

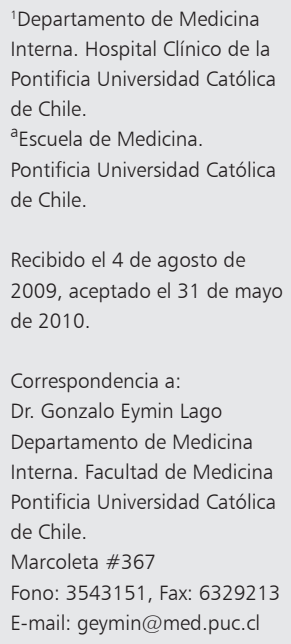

4 1 Streptococcus pyogenes (Estreptococo beta-hemolítico del grupo A (SBGA)), es una cocácea Gram positiva que produce infecciones localizadas y generalizadas, y secuelas inmunológicas (fiebre reumática y glomerulonefritis). Es causa frecuente de faringoamigdalitis e infecciones cutáneas, e inusualmente causa bacteriemia, neumonía, infecciones osteoarticulares y meningitis ${ }^{1}$. A pesar que las infecciones por SBGA presentan habitualmente un curso clínico leve, hasta $15 \%$ pueden evolucionar como enfermedad invasiva grave ${ }^{2}$. La incidencia de shock y bacteriemia por SBGA es de 0,18/100.000 admisiones hospitalarias, siendo factores de riesgo las neoplasias, diabetes, alcoholismo, inmunosupresión y el uso intravenoso de fármacos.

La neumonía por SBGA es infrecuente en adultos. Se describe como un cuadro rápidamente progresivo, a veces precedido por una infección respiratoria viral (influenza, varicela, sarampión), caracterizado por fiebre, dolor torácico de características pleuríticas y tos ${ }^{3}$. Puede complicarse con empiema, síndrome de distress respiratorio del adulto y síndrome de shock tóxico. La mortalidad llega a 38\% en mayores de 65 años y a 18\% en menores de esa edad, incrementándose en diabéticos independientemente de otras co-morbilidades ${ }^{4-6}$.

Se presenta a continuación un caso de bacteriemia por SBGA sin foco infeccioso evidente inicial, que evoluciona posteriormente con neumonía, forma de presentación diferente a las descritas en la literatura.

\section{Caso clínico}

Paciente de 58 años, diabética insulinorequirente, sin otros antecedentes mórbidos. Evaluada ambulatoriamente por cuadro de 2 días de náuseas y mareos diagnosticándose síndrome vertiginoso. Se realizó resonancia magnética de cerebro que mostró focos aislados de hiper-señal en sustancia blanca periventricular de carácter inespecífico. Se indicó antivertiginoso cediendo sintomatología. Una semana después inició cuadro de vértigo, náuseas y vómitos al menos 


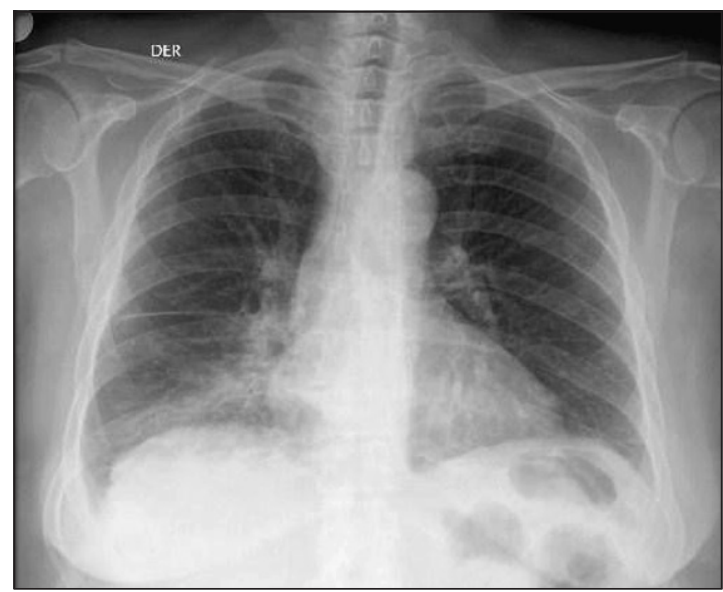

Figura 1. Radiografía de tórax muestra leve derrame pleural bilateral y tenues opacidades parenquimatosas confluentes en el lóbulo inferior derecho compatibles con foco de condensación.

en 20 ocasiones, asociado a fiebre hasta $38,5^{\circ} \mathrm{C}$. En revisión por sistemas destacaba orina de mal olor (sin otras molestias), y tos con expectoración blanquecina escasa de una semana de evolución. $\mathrm{Al}$ examen físico se encontraba en regulares condiciones generales, orientada, frecuencia cardíaca y respiratoria de 92 y 21 por minuto respectivamente, presión arterial de 120/66 mmHg y temperatura de $38,5^{\circ}$. Piel y mucosas deshidratadas, sin lesiones. Examen de cabeza, cuello y cardiopulmonar normal. Abdomen blando, sensible difusamente, sin signos peritoneales, con ruidos hidro-aéreos presentes. Se ingresó con diagnóstico de síndrome emético febril en estudio (probable foco urinario). Se solicitaron hemocultivos, sedimento urinario, urocultivo, radiografía de tórax, panel viral respiratorio, PCR para Influenza estacional y AH1N1. Se inició empíricamente ceftriaxona y levofloxacino el día de ingreso, agregándose ampicilina al segundo día por la presencia de una cocácea gram positiva en orina. Destacaban al hemograma 27.600 leucocitos (3\% baciliformes), y PCR en aumento en 3 días sucesivos (7,9-15,7-16,3 mg/dl) (Tabla 1), sedimento de orina con leucocitos +++ , bacterias ++++ , $\mathrm{pH}$ 6, urocultivo positivo a $S$. aureus meticilino sensible, y 2 hemocultivos positivos para SBGA multisensible. Panel viral y PCR Influenza AH1N1

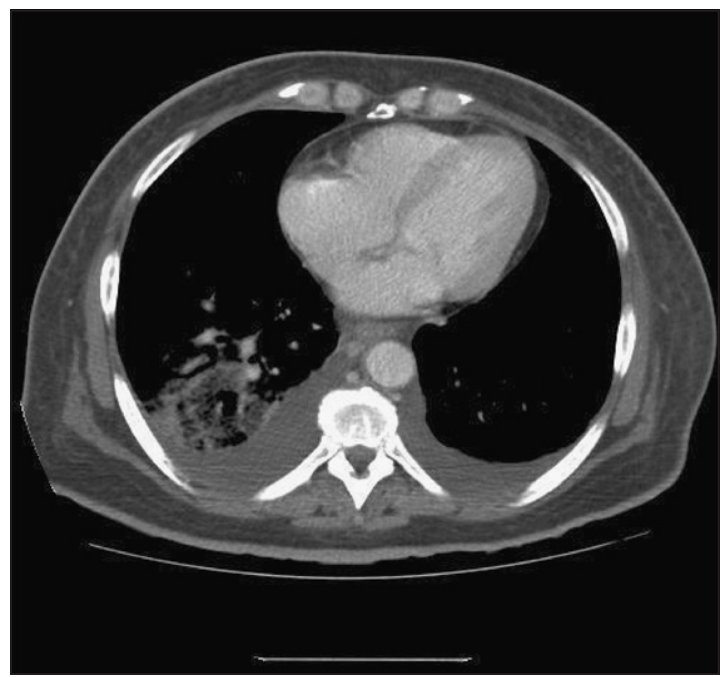

Figura 2. Tomografía computada de tórax muestra opacidad parenquimatosa de relleno alveolar en el lóbulo inferior derecho y leve derrame pleural bilateral, mayor a derecha.

negativos. Radiografía de tórax normal. Dado la bacteriemia por SBGA sin evidencia de foco primario, se solicitó ecocardiograma transesofágico que no mostró vegetaciones. Se administró ceftriaxona-levofloxacino y ampicilina por 3 días y luego se cambió por cefazolina 2 g cada 8 horas dado antecedente de alergia a penicilina y macrólidos e intolerancia conocida a la clindamicina. Evolucionó favorablemente, con disminución de los parámetros inflamatorios (PCR: $3,9 \mathrm{mg} /$ $\mathrm{dL}$ al tercer día), aunque con aumento de la tos y aparición de crépitos en base pulmonar derecha. Se repitió la radiografía de tórax en la que destacaba un foco de condensación, asociado a escaso derrame pleural en lóbulo inferior derecho. TAC de abdomen y pelvis realizado por sensibilidad abdominal confirmó neumonía basal derecha y descartó foco infeccioso en abdomen, pelvis, y en estructura ósea axial (Figuras 1 y 2). Se realizó búsqueda en la literatura en relación a SBGA para complementar con otros estudios que pudiesen orientar a foco primario sin encontrarse evidencia que avalara más exámenes. Se completaron 7 días de antibioticoterapia intravenosa y luego se otorgó el alta con cefadroxilo para completar 21 días. Al mes del alta, paciente se encontraba asintomática, con PCR de $0,0 \mathrm{mg} / \mathrm{dL}$, sin síntomas urinarios, respiratorios ni dolor lumbar. 
Tabla 1. Exámenes de laboratorio relevantes

\begin{tabular}{|lrrrrr|}
\hline Fecha & Día 0 & Día 1 & Día 2 & Día 6 & Día 30 \\
\hline Hematocrito $(\%)$ & 36 & 34,3 & 35,2 & 35,7 & 36,2 \\
\hline Leucocitos $\left(\mathrm{x} \mathrm{mm}^{3}\right)$ & 27.600 & 24.200 & 16.300 & 12.100 & 11.100 \\
\hline PCR $(\mathrm{mg} / \mathrm{dL})$ & 7,9 & 15,7 & 16,3 & 3,9 & 0,0 \\
\hline
\end{tabular}

\section{Discusión}

El Streptoccocus pyogenes es un patógeno frecuente en faringoamigdalitis e infecciones dermo-epidérmicas, que rara vez produce neumonías y bacteriemia ${ }^{7-8}$. La mayoría de los casos son esporádicos y adquiridos en la comunidad ${ }^{3-4}$. Su patogenicidad la debe a distintos constituyentes de su pared celular, y a productos extracelulares, como la proteína $\mathrm{M}$, el ácido hialurónico, los ácidos lipoteicoicos, enzimas y toxinas ${ }^{9}$. La proteína $\mathrm{M}$ es una proteína filamentosa de la membrana celular que presenta propiedades antifagocitarias, siendo los subtipos M1, 3, 12 y 28 los más frecuentemente asociados a infecciones graves en pacientes con shock y falla multiorgánica. Esta asociación requiere mayor investigación respecto a sus proyecciones clínicas. El estudio de un mayor número de cepas podría en el futuro permitirnos obtener información más concluyente respecto al pronóstico vital de un paciente ${ }^{10}$. Se han identificado tres tipos de exotoxinas estreptocócicas, la A, B y C. Las exotoxinas A y B se comportan como superantígenos, y se encuentran en la mayor parte de los pacientes con infecciones graves por SBGA.

El SBGA ingresa al organismo mediante la inhalación o microaspiración. Con menos frecuencia llega al pulmón por vía hematógena. La transmisión es por contacto persona-persona a través de secreciones durante un cuadro de faringitis. Excepcionalmente se ha descrito transmisión por alimentos ${ }^{14}$.

La presentación clínica y de laboratorio de la neumonía es similar a los casos de neumonía neumocócica ${ }^{3,11}$. Sin embargo, la neumonía por SBGA tiende a desarrollar derrame pleural más precoz y extenso, cultivos positivos de líquido pleural más frecuentemente, fiebre y períodos de hospitalización más prolongados. La radiología es característica, con aparición de infiltrados bronconeumónicos en lóbulos inferiores que se complican a las pocas horas con derrame pleural en el $55 \%$ a $95 \%$ de los casos $^{11}$. El líquido pleural tiene tendencia a tabicarse precozmente ${ }^{12,13}$. Los hemocultivos son positivos en el 7 a 16\% de los casos, y el cultivo del líquido pleural en el $20 \%$ a $40 \%{ }^{14-16}$

La neumonía por SBGA tiene una letalidad que va entre $38 \%$ y $47 \%$, de ahí que en presencia de compromiso de lóbulos inferiores y rápido desarrollo de derrame pleural, se deba sospechar neumonía por $\mathrm{SBGA}^{3,11}$. El tratamiento antibiótico con penicilina intravenosa asociada a clindamicina debe ser iniciado precozmente, $\mathrm{y}$ antes de recibir el estudio de sensibilidad ${ }^{17}$. Si se sospecha derrame pleural complicado debe instalarse con rapidez un tubo de drenaje pleural. La incidencia de neumonía por este microorganismo va en aumento (en concordancia al aumento en la incidencia de las infecciones invasivas). En una revisión se observa que en $81 \%$ de los casos la infección se adquiere en la comunidad y predominantemente en invierno. En $61 \%$ de los casos se acompaña de enfermedad crónica (predominando el compromiso pulmonar previo $)^{4}$.

A diferencia de otras cocáceas gram positivas, como Staphylococcus y Streptococcus pneumoniae, el SBGA se ha mantenido susceptible a la penicilina, por lo que esta sigue siendo el tratamiento de primera línea, y no se han descrito cepas resistentes. Los macrólidos, son la segunda elección, y de preferencia en pacientes con hipersensibilidad a la penicilina. En muchos países se ha incrementado el uso de eritromicina y de nuevos macrólidos ${ }^{17}$, con lo cual se ha incrementado la resistencia del Streptococcus pyogenes a esta familia de fármacos. En Chile, la resistencia del SBGA a los macrólidos se ha mantenido bajo $10 \%{ }^{18,19}$. En el Laboratorio Clínico de la Universidad Católica fueron aisladas 594 cepas de $S$. pyogenes entre 1990 y 1998, encontrándose 32 cepas resistentes $(5,4 \%)$.

Nuestra paciente tuvo un curso poco habitual, 
con aparición precoz de hemocultivos positivos para SBGA, sin sintomatología inicial ni exámenes que orientasen sobre un foco posible de infección, sumado a la ausencia de la sintomatología pulmonar rápidamente progresiva y grave descrita en los pacientes con neumonía por SBGA ${ }^{11}$. En esta paciente se utilizó cefazolina por alergia a la penicilina, dudosa alergia a macrólidos, e intolerancia conocida a clindamicina. La presencia de Staphylococcus aureus en orina en ausencia de cateterismo de la vía urinaria nos obliga a descartar un origen hematógeno, lo cual fue realizado con los hemocultivos y con un ecocardiograma trans-esofágico negativo para endocarditis, interpretándose como una bacteriuria asintomática ${ }^{20}$.

\section{Conclusión}

Si bien la neumonía por $S$. pyogenes es infrecuente en el adulto, su incidencia ha ido en aumento, y el riesgo de complicaciones como empiema, abscesos, síndrome de distrés respiratorio y shock séptico no son despreciables, describiéndose un curso rápidamente progresivo que se asocia a una alta mortalidad. El cuadro clínico-radiológico es similar al de la neumonía neumocócica, pero con una progresión más acelerada. La penicilina sigue siendo el tratamiento de elección.

Nos parece importante comunicar este caso clínico, dado la presentación atípica, con cultivos positivos antes que apareciera el cuadro clínico o radiológico clásico de neumonía, y sin las complicaciones graves asociadas, situación no descrita previamente en la literatura. Creemos derivado de esto que se debe tener en consideración el foco pulmonar en pacientes con bacteriemia por SBGA sin foco claro inicial, de modo de iniciar un tratamiento oportuno y evitar su progresión acelerada.

\section{Referencias}

1. Wald ER. Expanded role of group A streptococci in children with upper respiratory infections. Pediatr Infect Dis J 1999; 18 (8): 663-5.

2. Carapetis J, Robins-Browne R, Martin D, Shelby-James T, Hogg G. Increasing severity of invasive group A streptococcal disease in Australia: clinical and molecular epidemiological features and identification of a new virulent M-nontypeable clone. Clin Infect Dis 1995; 21 (5): $1220-7$.
3. Kalima P, Riordan T, Berrisford RG, Sarsfield PT. Necrotizing pneumonia associated with group A streptococcal bacteraemia. Eur J Clin Microbiol Infect Dis 1998; 17 (4): 296-8.

4. Muller MP, Low DE, Green KA, et al. Clinical and epidemiologic features of group a streptococcal pneumonia in Ontario, Canada. Arch Intern Med 2003; 163 (4): 46772.

5. Kornum JB, Thomsen RW, Riis A, Lervang HH, Schonheyder HC, Sorensen HT. Type 2 diabetes and pneumonia outcomes: a population-based cohort study. Diabetes Care 2007; 30 (9): 2251-7.

6. Kornum JB, Thomsen RW, Riis A, Lervang HH, Schonheyder HC, Sorensen HT. Diabetes, glycemic control, and risk of hospitalization with pneumonia: a population-based case-control study. Diabetes Care 2008; 31 (8): 1541-5.

7. Carapetis JR, Steer AC, Mulholland EK, Weber M. The global burden of group A streptococcal diseases. Lancet Infect Dis 2005; 5 (11): 685-94.

8. Saldías F, Yáñez J, Saldías V, Díaz O. [Communityacquired pneumonia caused by Streptococcus pyogenes: report of one case]. Rev Med Chile 2008; 136 (12): 1564-9.

9. Tart AH, Walker MJ, Musser JM. New understanding of the group A Streptococcus pathogenesis cycle. Trends Microbiol 2007; 15 (7): 318-25.

10. Ulloa FM. Caracterización molecular de cepas de Streptococcus pyogenes aisladas de cuadros invasores basada en el polimorfismo del regulón vir. Rev Chil Infectol 2001; 18 (3).

11. Al-Kaabi N, Solh Z, Pacheco S, Murray L, Gaboury I, Le Saux N. A Comparison of group A Streptococcus versus Streptococcus pneumoniae pneumonia. Pediatr Infect Dis J 2006; 25 (11): 1008-12.

12. Braman SS, Donat WE. Explosive pleuritis. Manifestation of group A beta-hemolytic streptococcal infection. Am J Med 1986; 81 (4): 723-6.

13. Sharma JK, Marrie TJ. Explosive pleuritis. Can J Infect Dis 2001; 12 (2): 104-7.

14. Chalasani NP, Valdecanas MA, Gopal AK, McGowan JE, Jr, Jurado RL. Clinical utility of blood cultures in adult patients with community-acquired pneumonia without defined underlying risks. Chest 1995; 108 (4): 932-6.

15. van der Eerden MM, Vlaspolder F, de Graaff CS, Groot T, Jansen HM, Boersma WG. Value of intensive diagnostic microbiological investigation in low- and high-risk patients with community-acquired pneumonia. Eur J Clin Microbiol Infect Dis 2005; 24 (4): 241-9.

16. Waterer GW, Wunderink RG. The influence of the severity of community-acquired pneumonia on the 
usefulness of blood cultures. Respir Med 2001; 95 (1): 78-82.

17. Horn DL, Zabriskie JB, Austrian R, et al. Why have group A streptococci remained susceptible to penicillin? Report on a symposium. Clin Infect Dis 1998; 26 (6): 1341-5.

18. Camponovo R. Problemas de resistencia en Streptococcus pyogenes. Rev Chil Infect 2002; 19 (Supl 2): S107110.
19. Palavecino EL, Riedel I, Berrios X, Bajaksouzian S, Johnson D, Kaplan E, Jacobs MR. Prevalence and mechanisms of macrolide resistance in Streptococcus pyogenes in Santiago, Chile. Antimicrob Agents Chemother 2001; 45 (1): 339-41.

20. Sheth S, DiNubile MJ. Clinical significance of staphylococcus aureus bacteriuria without concurrent bacteremia. Clin Infect Dis 1997; 24 (6): 1268-9. 